\title{
Topical Application of Human Milk versus Alcohol and Povidine-Iodine on Clinical Outcomes of Umbilical Cord in Healthy Newborn: Impact of an Educational Program of Mothers' Knowledge and Practice Regarding Umbilical Cord Care
}

\author{
Hanan Elzeblawy Hassan ${ }^{1}$, Sahar Sedky Faheim ${ }^{2} \&$ Wafaa Mostafa Ahmed Gamel ${ }^{3}$ \\ ${ }^{1}$ Maternal and Newborn Health Nursing, Faculty of Nursing, Beni-Suef University, Egypt \\ ${ }^{2}$ Pediatric Nursing, Faculty of Nursing, Beni-Suef University, Egypt \\ ${ }^{3}$ Maternal and Neonatal Health Nursing, Faculty of Nursing, El-Fayoum University, Egypt \\ Correspondence: Hanan Elzeblawy Hassan, Maternal and Newborn Health Nursing Department, Faculty of \\ Nursing, Beni-Suef University, Egypt
}

Received: April 2, 2019

doi:10.20849/ijsn.v4i2.573
Accepted: April 30, 2019

Online Published: May 5, 2019

URL: https://doi.org/10.20849/ijsn.v4i2.573

\begin{abstract}
Aim: This quasi-experimental study was conducted to evaluate the effect of an educational program of mothers' knowledge and practice about umbilical cord care; compare cord-cleansing using human milk versus alcohol $70 \%$ and povidine-iodine $10 \%$ on clinical outcomes of umbilical cord in healthy newborn. Subjects: A total of 150 mothers who had just delivered with their newborn infants at the postnatal units at El-Fayoum University Hospital, Egypt, were recruited for this study. Tool: data was collected through a structured interview questionnaire; newborn follow-up sheet and an observation checklist. Results indicated that, before the intervention of the educational program, lake of satisfactory knowledge and practice among mothers in all groups related to cord care. The total mean scores for the immediate post/follow up tests of intervention educational program were statistically significantly higher $(p<0.001)$, compared to their pre-intervention of the educational program scores. Concerning newborn follow-up, there were highly statistically significant differences in umbilical cord base separation time, the sign of cord infection, bleeding continuation in mother milk group as compared with alcohol $70 \%$ and povidine-iodine $10 \%$ group. Conclusion: Educational program had a positive effect on mothers' knowledge and competency of their practice regarding umbilical cord cleansing. Topical application of mother milk on umbilical cord care leads to rapid cord separation time; diminish the umbilical cord infection as it can be used as an easy, cheap and non-invasive way for cord care. Recommendation: educational programs intervention regarding neonatal care is required during the period of antenatal visit. Researches to study the effect of newborn cord care practices on the incidence of newborn morbidity/mortality are required.
\end{abstract}

Keywords: newborn, educational program, umbilical cord care, clinical outcomes, mothers' knowledge and practice

\section{Introduction}

The most vital time for the mother and their newborn is during birth and the hours and days immediately after childbirth. Around 75 percent of neonatal deaths happen during the $1^{\text {st }}$ week of life, with the majority in the $1^{\text {st }}$ 48 hours due to infectious causes (Elsobky, et al., 2017). Neonates dies from situations and diseases associated with a lack of quality care at birth or improper skilled care and management immediately after birth (Castalino et al., 2014). World Health Organization (WHO) recommends vital newborn care practices including promotion and support for early beginning of exclusive breastfeeding, thermal protection including promoting skin-to-skin contact, hygienic and umbilical cord care to decrease neonatal mortality and morbidity rate (Mohamed, 2018). The umbilical cord stump infections are the most common reason of a newborn morbidity and mortality in numerous developing countries, due to poor of hygienic care. According to a recent WHO anticipated that 4 million neonates die annually during the neonatal period (Mahrous et al., 2012). Pregnant women and young children in Egypt face tenacious health challenges. In Egypt, Neonatal mortality has been deteriorating more 
slowly than under-five mortality and currently accounts for $52.0 \%$ of all under-five deaths (lawn et al., 2010; WHO, 2017).

Ministry of Health and Population, Egypt, reported that, newborn infants are at risk for several health problems, even though they are born with average birth weights. The morbidity and mortality rates in newborn infants are great, and they need the best care for enhanced survival, being spread to more sensitive individuals in the family (MOH, Egypt, 2014). Neonates are also at risk from motherly infection if hygiene is not adequate and good by nurses; mothers would decrease the likelihood of cold, dermatitis, herpes, and skin diseases. The everyday cleansing of the infant gives an excellent opportunity for making the observation that necessary during the immediate postnatal period (Shahjahan et al., 2012). Neonatal care is extremely expensive because saving the life of a neonate is associated with survival and productivity of the future adult. Although parents are eventually responsible for this care, nurses ordinarily assume a major caregiving role while the infant is in the nursery (Mohamed, 2018).

Although the umbilical cord is the life giver, it could be also a life threatened of the newborns by acquiring infection via its vessels to the newborns' bloodstream. So, corrected and adequate umbilical cord care is very essential for infection prevention in the neonatal period (Abbaszadeh, et al., 2016). Umbilical cord cares, after natal until for its separation is a vital component in newborn care. Usually, the umbilical cord can become colonized with possible pathogenic microbes during the intrapartum or postpartum period. These pathogenic microorganisms are likely to invade the umbilical stump, which can lead to omphalitis. Data on the prevalence of omphalitis in low-income countries is usually rare; the available data estimate the threat to range between 2 and 77 per 1000 live births in hospital settings, with fatality rates of between $1.0 \%$ and $15.0 \%$ depending on the definition of omphalitis used (Elsobky, et al., 2017). The cord stump colonization by pathogenic bacteria leading to infection can source of morbidity and mortality of newborn especially in the developing countries (Mahrous et al., 2012).

Despite the fact that there is a general agreement about the cleans technique for cutting the cord using a sterile cutting instrument (blade or scissors) and clean hands to avoid infection, there is less agreement on what is the best care of the cord stump (Karumbi, 2013). In many cultures, some materials are applied to the umbilical cord stump and are linked with high-risk of infection (Zupan, 2004; sinah et al., 2015); as ashes, oil, butter, spice pastes, herbs and mud (Adebami, 2014). These materials are often contaminated with microbes and bacterial spores that increase the incidence of complications like cord sepsis, septicemia, umbilical cord granuloma, excessive bleeding, Omphalitis, and tetanus. These situations contribute significantly to neonatal morbidity and mortality (Mahrous et al., 2012). Appropriate cord care consequently, gives largely to the well-being of the newborn (Adebami, 2014). The separation time of umbilical cord can be affected by how clean umbilical cord care, humidity cord, environmental sanitation around the newborn. In addition, influences that delay the process of cord stump separation are the application of antiseptics to the cord stump, the incidence of infection of the umbilical cord and cesarean section (Mohamed, (2018).

The umbilical cord stump infection can be prevented by many efforts; from the methods are used, for example using an antiseptic solution such as alcohol $70.0 \%$, povidine-iodine (Betadine) $10.0 \%$, for a traditional method by using honey, ghee oil (India), or colostrum (Sofiana, 2011). In some countries, umbilical cord stump infection cases are preserved by using aseptically technique. Other countries worried to protect the umbilical cord stump from infection by smearing topical breast milk. Some researchers showed smearing topical breast milk shortening umbilical cord stump separation time compared to antiseptic or non-antiseptic treatment. The treatment costs vary according to the method used. Hence, it is important to discovery cheap alternative care; for example, human-breast-milk, especially, for low-income countries (Mahrous et al., 2012). Human-breast-milk identified as liquid gold as it is a deep yellow serous fluid containing a lot of antibodies; IgA, IgG, and IgM. It seems to have an impact on preventing skin infection. Also have effect as antibacterial, antiviral, supporting body immune, promote regaining and musculoskeletal growth as well (Elsobky, et al., 2017; Daiahunlin, 2017; Abd-Allah et al., 2017; Chawla \& Diwaka, 2015). According to the WHO, up-to-date application of human-breast-milk to the umbilical cord stump can be valuable due to its antibacterial factors, in addition to immunologic and anti-infective agents. Colostrum comprises significant amounts of balance components that act as natural antimicrobial agents, in addition to defensive factors that provide specific and non-specific passive immunity (Golshan, \& Hossein, 2013).

So, a vital role of maternity and newborn practical nurses is performing cord care at birth and in the day's subsequent birth which is effective in preventing cord infections. Clean cord-care practices comprise washing hands with clean water and soap before labor and wear sterile gloves before cutting the cord, cutting the cord with sterile equipment, protection the cord stump from wetting or moist, exposed to air or lightly covered with 
clean clothes (Sawardekar, 2004; Abd-Allah, 2017). Other skills which the nurses should do that may decrease the hazard of cord infection are the use of 24-hours rooming-in in its place of nurseries in institutions and skin-to-skin contact with the mother at birth to promote colonization of the newborn with non-pathogenic microbes from the mother's skin flora. Also, nurses should encourage initial and frequent breastfeeding that will provide the newborn with antibodies against infections (Nandrup-Bus et al., 2003). Umbilical cord care is a part of the routine duties of the maternal and newborn and pediatric nurses after baby bath every day in the hospital. Before mother discharge, the maternity \& newborn as well as pediatric nurses should be educated about umbilical cord care at home. Nurses normally provide umbilical cord care for babies and mothers care skills and discover new parents often complain about problems such as delay in umbilical cord separation, blood/serous secretions, odor, and umbilical cord infection when they admission clinic visits or call telephone helplines. This shows the necessity and the request from new mothers and nurses to advance the umbilical cord care according to evidence-based practice (Huang, 2013).

Educational programs with effective training strategies encourage mothers to follow healthy practices in day-to-day life. The vital educative role of maternity/pediatric nurses wants to be emphasized. Furthermore, a healthy newborn is directly connected to healthy maternal and hence improving birth outcomes depends on also improving maternal health care throughout pregnancy through antenatal care, skilled delivery, and the postpartum period by providing postpartum care (Moyer et al., 2012).

\subsection{Significant of the Study}

Umbilical cord infection are considered a vital contributing factor for the increased morbidity and mortality of neonates in developing countries (Dhanawade, 2014). The newborn infant mortality rate in Egypt was 14 deaths per 1,000 births (MOH, Egypt, 2014). Yearly, about 3.3 million neonatal deaths happen around the world; more than $30.0 \%$ are caused by infections. Some of these infections start as umbilical cord infection (Elsobky, et al., 2017). Mother's education of neonatal care practices and the improvement of the role of maternity/pediatric nurses can lead to enhancements of the mother's outcome of care during postnatal period. However, the smallest researches regarding newborn cord care procedure were observe amongst mothers in Egypt, and most newborn-care practices such as cord care are carried out by their mothers. Therefore, this study aimed to evaluate newborn cord care knowledge and practices among mothers in order to inform policy and progress of feasible and supportable maternal and child health-based interventions that can improve the wellbeing of the newborn infant.

Umbilical cord infection is the main cause of neonates' deaths since infection of the cord may be fatal. Notwithstanding the importance of umbilical-cord-care, either traditionally or medically, there have been insufficient randomized trials, investigating the impact of different cord care routine on umbilical cord separation time, mainly in developing countries. Several agents have been used for umbilical-cord-care. The most commonly used agents include triple dye, silver sulfadiazine, alcohol, chlorhexidine $0.5 \%$, and bacitracin (Karumbi, 2013). As the human mothers' milk doesn't cost anything, sterile, available, easily used and noninvasive way for the cord care, it is vital to explore the possibility of using human others' milk topically to protect infants from umbilical cord infections in developing countries. A search of the literature found no study that compared human milk with alcohol $70.0 \%$ and povidine iodine $10.0 \%$ in El-Fayoum university hospital. So, the researchers decided to evaluate the effect of an educational program of mothers' knowledge and practice about umbilical cord cleansing using human milk, alcohol $70.0 \%$ and povidine iodine $10.0 \%$ on clinical outcomes of umbilical cord in healthy newborn.

\subsection{Aim of the Study}

The study aimed to evaluate the impact of an educational program of mothers' knowledge and practice about umbilical cord cleansing. Moreover, compare usage of human milk versus alcohol $70.0 \%$ and povidine-iodine $10.0 \%$, for cord cleansing, on clinical outcomes of the healthy newborn. The clinical outcome of umbilical cord includes cord separation time, signs of umbilical cord infection and bleeding continuation after separation.

\subsection{Hypothesis}

H1: The educational program will have a positive effect on mothers' knowledge and competency of their practice about umbilical cord cleansing technique, regardless of the liquid used for cleansing.

H2: The clinical outcome of umbilical cord of the healthy newborn (cord separation time, signs of umbilical cord infection and bleeding continuation after separation) will be better among babies whose mothers used human-breast-milk for cord cleansing rather than other groups who used alcohol $70.0 \%$ and povidine iodine $10.0 \%$. 


\section{Subjects and Methods}

\subsection{Research Design}

A quasi-experimental design was be utilized for the study.

\subsection{Research Setting}

The study was conducted in the postpartum unit of obstetrics and gynecology department at El-Fayoum University Hospital.

\subsection{Sample}

A Purposive sampling; a total of 150 healthy newborn-mother pairs were recruited in the study and fulfills the inclusion criteria. The sample was randomly allocated into three main groups; 50 in mother milk group, 50 in alcohol $70.0 \%$ and 50 in povidine-iodine $10.0 \%$ group.

\subsubsection{Inclusion Criteria}

\subsubsection{1 for Mothers}

Mothers willing to co-operate for intervention and apply their breast milk to their babies' umbilical cord.

Had no maternal complications.

Mother with normal breastfeeding.

\subsubsection{2 for Neonate}

Newborns from the first day of life.

Healthy and full term (38-42 weeks) neonate.

Apgar score $>7$ at 1 and 5 minutes.

Normal birth weight from 2.5 to $3.5 \mathrm{~kg}$.

Free from any medical complication or disorder.

Rooming in with the mother.

An absence of congenital anomalies

\subsubsection{Exclusion Criteria}

\subsubsection{1 for Mothers}

Mother with contraindicated of normal breastfeeding.

\subsubsection{2 for Neonate}

Newborns those are sick, unstable, and critically ill.

Newborns admitted to a neonatal intensive care unit (NICU).

Newborns that are having congenital anomalies.

Premature, preterm, low birth weight babies (LBW).

Newborns receiving antibiotics.

Gestational age of more than 42 weeks.

Apgar scores less than 7 degrees.

\subsection{Tools of Data Collection}

Three tools were developed for collecting data.

Tool I: Structured Interview Schedule: It was developed by the research team after reviewing the related literature (Nandrup-Bus and Ugeskr, 2003; Shahjahan, et al., 2012; MOH, Egypt, 2014). It was conducted to collect data related to the mothers and their newborns. This tool included three parts:

- Part A: Demographic characteristics and obstetrical history of mothers, such as; age, educational level, residence, employment status, numbers of gravidity, and numbers of parity, mode of delivery and their sources of information.

- Part B: Demographic and general characteristics of neonates, such as gestational age, gender, birth weight, and Apgar score.

- $\quad$ Part C: Mother's knowledge: To assess mothers` knowledge regarding umbilical cord cleansing such as (definition of typical cord care, factors affecting on cord healing, method and material for securing umbilical cord, solution used for cleaning cord time of separation, signs of inflammation and infection, and 
umbilical cord care benefits).

Scoring system: Knowledge content was divided into 7 questions and each question was assigned to three score levels: Complete and/or correct answer was scored (3 points), while incomplete correct answer was scored (2 points), and don't know or the wrong answer was scored ( 1 point). The total score was categorized into either satisfactory level from $70.0 \%$ and more $(\geq 14$ points) or unsatisfactory level less than $70.0 \%$ ( $<14$ points) from the total score (21 points).

Tool II: An observational checklist: Adapted from Whitmore (2010), Wilson \& Hockenberry, (2014), to observe the actual mothers' practice for umbilical cord cleansing.

Scoring system: practice content was divided into 12 steps and each step was assigned to two score levels, which are: done was scored ( 2 points), and not done scored ( 1 point). The total score was categorized into either competent from $70.0 \%$ and more ( $\geq 16$ points) or incompetent less than $70.0 \%$ ( $<16$ points) from the total score (24 points).

Tool III: Follow up an observational-checklist for monitoring signs of cord healing, cord separation time and signs of cord infection.

This checklist was developed by the researchers and completed by them. It was based on the objectives of their study. This included one part: it was a checklist to checking the presence or absent the signs of cord infection as (high body temperature, warmth and mild redness, moderate or severe redness, severe redness with pus, foul odor of cord and cord exudate) monitoring cord separation time till cord separation occurs.

\subsection{Methods of Data Collection}

This study was covered in the following phases:

\subsubsection{Validity and Reliability of Tools}

Data collection tools were submitted to five experts in the field of 1 neonatology, 2 maternity/obstetric, and 2 pediatric nursing to test content validity. Their opinions were elicited regarding the tools format layout, consistency, scoring system. Modifications for the tools were done according to the experts' judgment on the clarity of sentences, appropriateness of content and sequence of items. The experts were agreed on the intervention but recommended minor language skills changes that would make the information clearer and more précis. Alpha Cronbach test $=0.86$ for testing reliability if tools.

\subsubsection{Administrative Considerations}

Necessary approval from El-Fayoum University hospital director was taken after issuing an official letter from the dean of the Faculty of Nursing, El-Fayoum University.

\subsubsection{Ethical Considerations}

All engaged mothers were informed that participation is voluntary and have the right of accepting or refusing participation in the study. Every mother was informed about the objectives of the study and its benefits, in order to obtain her acceptance to participate. The researchers informed all of them that the participation in the study is voluntary, and they have the right to take-out from the study at any time, without giving any reason and their answers would be held confidentially. Privacy and confidentiality of all the data will be secured. Informed consent was gained from those who welcome to participate in the study.

\subsubsection{A pilot Study}

A pilot study was carried out on $10.0 \%$ of the total sample (15) of the total sample to test and ensure the clarity/applicability of all study tools as well as estimation of the time needed to fill the questionnaire. According to the pilot study results, the necessary modifications were done. All mothers and their neonates participated in the pilot study were excluded from the study.

\subsubsection{Field Work}

After obtaining official permission from the director of El-Fayoum university hospital and agreement of the chairman of obstetrics and neonatology department, data were collected through a period of nearly 15 months from the beginning of October 2017 to the end of December 2018. The researcher started the study by visiting the sitting of the study three-days/week namely; Saturday, Monday \& Wednesday, from 10.00 am to $3.00 \mathrm{pm}$. The data collection authorized researcher introduced herself and clarified the aims of the study to all mothers who met the criteria for inclusion in the sample. Each mother was randomly assigned to the line of treatment. The researcher engaged the odd numbers in mother milk group and the even numbers in alcohol $70.0 \%$ and povidine-iodine $10.0 \%$ group.

The data were collected, from the studied mothers, through interviewing questionnaire and a follow-up 
observational checklist for monitoring signs of cord healing, cord separation time and signs of cord infection. The researcher obtained the participants' approval to engage in the study. The researcher collected socio-demographic and obstetrical data related to the mother's age, educational level, residence, and parity, and data related to the neonate as gestational age, gender, and birth weight. For data related to mother culture, beliefs and habits about cord care; the researcher asked questions in a simple Arabic language and documented the answers in the structure interview tool. Interview consumed about 30-45 minutes for each. Data were collected through 4 phases: assessment, planning, implementation, and evaluation \& follow-up phases.

(1). Assessment phase: pretest was done for all (150) mothers in the three groups to evaluate mothers baseline knowledge and practices in relation to newborn cord care. The researcher met with mothers and their newborn infants in the postnatal units for a clear and simple clarification of the aim and nature of the study. Those who fulfilled the inclusion criteria and gave their consent were engaged in the study sample. Each mother was asked to demonstrate the newborn cord care as a pretest and was observed using the corresponding checklist; it took about 25-35 minutes.

(2). Implementation Phase: during this phase, the researchers prepared and designed educational program in simple Arabic language based on relevant literature review; it included knowledge and the steps of newborn cord care practices with exemplified pictures to facilitate the teaching of practices.

(3). Implementation Phase: the researchers gave general instructions and educational message, to all participating mothers, regarding hygienic of umbilical cord care and the surrounding skin, moreover, demonstrated the ideal technique for cleaning the umbilical cord stump and the surrounding skin area. Steps of cord care were educated with teaching materials and demonstrated by the researcher and re-demonstration was carried out by each mother individually on a small doll. The researcher observed each studied mother and reassured the mother if any errors were committed; it took about 20 to 30 minutes for each one. All mothers are recommended to wash their hands with water and soap prior to implementation of the umbilical cord stump care to ensure safety and prevention of infection. Mothers were asked to re-demonstrate the procedure and instructed to apply it every 8 hours ( 3 times per day) and as needed during diaper care until two days after umbilical-cord-separation. Group (A): Mothers instructed after washing their hands to scrub their breast milk (before lactation) on the remaining part of the cord about (4-6 drops) and its cut edge and let the milk get completely dry on the cord and should to be beginning 3 hours after birth once every 8 hours (three times a day) till 2 days after the cord separation. Mothers instructed that nothing is applied to the cord stump, including a topical agent, with breast milk and keep the diaper folded under the umbilical stump area to enhance dryness, healing, and prevent contamination. Group (B): The umbilical cord of the involved neonates was cut, in the delivery room, with aseptic technique. Mothers were asked to re-demonstrate and clean the cord stump with $70.0 \%$ alcohol by sterile gauze or swab starting three hours after birth and continued every 8 hours as needed during diaper changes till two days after umbilical-cord-separation and no other antiseptic agent was used on the cord stump. Group (C): The umbilical cord of the involved sample was cut, in the delivery room, in a sterile condition. Mothers were asked to clean the cord stump with $10.0 \%$ povidine-iodine by a sterile gauze or swab starting three hours after birth and continued every 8 hours as needed during diaper changes till two days after umbilical cord separation and no other antiseptic agent was used on the cord stump. Mothers in all groups were instructed to not to cover the cord stump with diapers and not to bath the newborns in bathtub till the cord is separated. Moreover, a sponge bath is better method during the healing process. Total observation is done within the $1^{\text {st }}$ three hours after birth at hospital and in the $4^{\text {th }} \& 8^{\text {th }}$ days as well as 2 days after fall-off umbilical cord stump. For observing and follow-up for signs of cord infection, the researcher follow-up the compliance of mothers regarding instructions of cord care using a checklist, signs of cord infection were observed by naked eye. Determination of the day of cord separation was done by documented daily phone call until the cord falls off. The duration of umbilical cord separation was measured from newborn birthday to separation date day. The mothers educated how to fill this sheet. All mothers were asked to continue completing the forms until 2 days after fall-off the cord. All mothers had got educational program booklet forms which developed by the researchers, to remind them the complete and correct steps of procedure and the exact time of mother's milk or alcohol or povidine-iodine application during the day, before their discharge from the hospital included: method of cord care, time of cord separation and when to call the researchers to make referral to the pediatrician (if the baby has a fever or if the umbilical area seems red and swollen around the cord; crying when the mother touches the cord or skin around it; remains to bleed; or oozes yellowish pus; and produces a foul-smelling discharge). In order to make sure the presence of the infection, researchers observed umbilical cord and in cases of delay in cord separation or any cord related adverse events such as blood leakage, the newborn was immediately visited by a neonatologist. The cord generally falls off in $7^{\text {th }}$ to $10^{\text {th }}$ days. 
(4). Evaluation \& follow-up phase: The effect of cord care educational program on mothers' knowledge and competency of their practice, about umbilical cord cleansing technique regardless of the liquid used for cleansing, was evaluated immediately after the intervention phase, it took about 20 mints, as well as one month later (follow-up), using the same previously mentioned tools and checklist. Additionally, the clinical outcome of umbilical cord of the healthy newborn (cord separation time, signs of umbilical cord infection and bleeding continuation after separation) among babies whose mothers used human-breast-milk for cord cleansing was compared with other groups who used alcohol $70.0 \%$ and povidine iodine $10.0 \%$ throughout the study period $\left(4^{\text {th }}\right.$ $\& 8^{\text {th }}$ days after delivery and 2 days after umbilical cord separation).

\subsubsection{Statistical Design}

The collected data were organized, tabulated and statistically analyzed using SPSS software, version 21. For Quantitative data, the range, mean and standard deviation were calculated. For qualitative data, the comparison between two groups and more was done using Chi-square test $\left(\mathrm{x}^{2}\right)$. The $\tau$-test was used to liken between sample means for quantitative data with normal distribution (pre-post). ANOVA test used to compare the means of three groups on the dependent variable. Level of significance $p<0.05,0.01,0.001$ were used as the cut of value for statistical significance. Graphical presentation presented by 3-D column and Bar of Pie chart diagram.

\section{Results}

Table 1 Shows that the mean age of the mothers was $28.32 \pm 3.4$ years in mother milk group compared to 27.96 \pm 3.2 and $27.22 \pm 2.9$ years in alcohol group and povidine iodine group, respectively. More than half $(66.0 \%$ \& $64.0 \%$ ) of mothers live in rural area in mother milk and alcohol groups, respectively, comparing to $46.0 \%$ in povidine iodine group. Most of the participant mother were multiparous (90.0\%, 70.0\%, 64.0\%, respectively) and delivered by cesarean section $(56.0 \%, 62.0 \%, 56.0 \%$, respectively), with a non-significance difference ( $>0.05$ ) between all groups which indicates homogeneity of all groups.

The neonates' characteristics are presented in Table 2. It was revealed that female infants constitute around two-thirds $(68.0 \%$ and $62.0 \%)$ of the breast milk and povidine iodine group, while $58.0 \%$ of the alcohol group were male infants. All three groups were compared, no significant differences in respect to baseline characteristics as neonatal birth weight, Apgar score, sex of newborn and gestational age ( $>0.05)$.

Figure 1 illustrates that the main source of information for mothers was their family (45.0\%), followed by friends $(30.0 \%)$, then, health care team $(15.0 \%)$, and the least one was mass media $(10.0 \%)$.

Table 3 shows studied mothers' satisfactory level of knowledge about umbilical cord cleansing using human milk versus alcohol $70.0 \%$ and betadine $10.0 \%$ in pre/posttests. Results indicated significant improvement in mothers' knowledge as regards post and follow-up tests after program implementation. The mean percent's baseline knowledge before program implementation (pre-test) compared to after program implementation (post-test) were $25.2 \pm 8.7,92.7 \pm 3.1 \& 84.1 \pm 2.9$ for human milk group versus alcohol $70 \%$ group \& povidine-iodine $10 \%$ group, respectively, at $\mathrm{p}<0.001$.

Figure 2 portrays the studied mothers' total knowledge score about umbilical cord cleansing. The majority of them $(83.0 \%)$ had an unsatisfactory level of knowledge before educational program implementation, which improved for the majority of them $(95.0 \%)$ to satisfactory immediately post educational program implementation. However, the same figure shows that the majority of studied mothers $(92.0 \%)$ had a satisfactory level and their total knowledge scores remaining competent in the follow-up phase of educational program implementation, with a highly statistically significant difference $(\mathrm{p}<0.001)$.

Figure 3 describes the studied mothers' total practice score about umbilical cord cleansing. The majority of them $(87.0 \%)$ had an unsatisfactory level and incompetent practices before educational program implementation, which improved for most of them $(95.0 \%)$ to satisfactory and competent practices immediately post educational program implementation. However, the same figure illustrates that the majority of studied mothers $(91.0 \%)$ had a satisfactory level and their total practice scores remaining competent in the follow-up phase of educational program implementation, with a highly statistically significant difference $(\mathrm{p}<0.001)$.

Table 4 and Figure 4 Show a highly significant difference between the all groups as regards cord separation times, it showed that the majority $(90.0 \%)$ of mother milk group; the cord was separated less than one week as compared to $(10.0 \%)$ in alcohol group and $(4.0 \%)$ in povidine-iodine group $(\mathrm{p} \leq 0.001)$.

Table 5 shows that, the signs of cord infection and complications were less in the mother milk group as compared to alcohol and povidine-iodine groups during the first and second follow-up visits.

Table 6 Reveals, a highly significant difference $(p<0.001)$ between mother milk, alcohol, and povidine-iodine groups regarding the mean scores of cord-bleeding continuations. It shows lesser bleeding continuation in infants 
whose mothers used breast milk $(1.34 \pm 0.60)$ than others who used alcohol and povidine-iodine group $(2.54 \pm$ $0.69 \& 3.46 \pm 0.81)$, respectively.

Table 1. Distribution of the studied mothers sample according to their socio-demographic and obstetrical characteristics ( $\mathrm{n}=50$ each group)

\begin{tabular}{|c|c|c|c|c|c|c|c|}
\hline Characteristics & \multicolumn{2}{|c|}{$\begin{array}{l}\text { Human milk } \\
\text { (group 1) }\end{array}$} & \multicolumn{2}{|c|}{$\begin{array}{l}\text { Alcohol 70\% } \\
\text { (group 2) }\end{array}$} & \multicolumn{2}{|c|}{$\begin{array}{l}\text { Povidine iodine } \\
10 \% \text { (group } 3 \text { ) }\end{array}$} & $\begin{array}{c}\chi^{2} \\
\text { p value }\end{array}$ \\
\hline $\begin{array}{l}\text { Mother's Age(years) } \\
\text { Mean } \pm \text { SD }\end{array}$ & \multicolumn{2}{|c|}{$28.32 \pm 3.4$} & \multicolumn{2}{|c|}{$27.96 \pm 3.2$} & \multicolumn{2}{|c|}{$27.22 \pm 2.9$} & $>0.05$ \\
\hline $\begin{array}{l}\text { Residence } \\
\text { Urban } \\
\text { Rural }\end{array}$ & $\begin{array}{l}22 \\
28\end{array}$ & $\begin{array}{l}44.0 \\
66.0\end{array}$ & $\begin{array}{l}18 \\
32 \\
\end{array}$ & $\begin{array}{l}36.0 \\
64.0\end{array}$ & $\begin{array}{l}27 \\
23\end{array}$ & $\begin{array}{l}54.0 \\
46.0\end{array}$ & $\begin{array}{c}0.241 \\
P>0.05\end{array}$ \\
\hline $\begin{array}{l}\text { Occupation } \\
\text { Work } \\
\text { Housewife }\end{array}$ & $\begin{array}{l}16 \\
34\end{array}$ & $\begin{array}{l}32.0 \\
68.0\end{array}$ & $\begin{array}{l}23 \\
27\end{array}$ & $\begin{array}{l}46.0 \\
54.0\end{array}$ & $\begin{array}{l}19 \\
31\end{array}$ & $\begin{array}{l}38.0 \\
62.0\end{array}$ & $\begin{array}{c}2.02 \\
P>0.05\end{array}$ \\
\hline $\begin{array}{l}\text { Education } \\
\text { Illiterate } \\
\text { Primary } \\
\text { Secondary } \\
\text { University }\end{array}$ & $\begin{array}{c}8 \\
15 \\
18 \\
9\end{array}$ & $\begin{array}{l}16.0 \\
30.0 \\
36.0 \\
18.0\end{array}$ & $\begin{array}{c}5 \\
10 \\
14 \\
21\end{array}$ & $\begin{array}{l}10.0 \\
20.0 \\
28.0 \\
42.0\end{array}$ & $\begin{array}{c}4 \\
15 \\
18 \\
13\end{array}$ & $\begin{array}{c}8.0 \\
30.0 \\
36.0 \\
26.0\end{array}$ & $\begin{array}{c}0.241 \\
P>0.05\end{array}$ \\
\hline $\begin{array}{l}\text { Gravidity } \\
\text { Primipara } \\
2^{\text {nd }} \\
3^{\text {rd }} \\
\text { Grand multi }\end{array}$ & $\begin{array}{c}8 \\
11 \\
18 \\
13\end{array}$ & $\begin{array}{l}16.0 \\
22.0 \\
36.0 \\
26.0\end{array}$ & $\begin{array}{c}12 \\
10 \\
20 \\
8\end{array}$ & $\begin{array}{l}24.0 \\
20.0 \\
40.0 \\
16.0\end{array}$ & $\begin{array}{c}9 \\
13 \\
20 \\
8\end{array}$ & $\begin{array}{l}18.0 \\
26.0 \\
40.0 \\
16.0\end{array}$ & $\begin{array}{c}0.31 \\
P>0.05\end{array}$ \\
\hline $\begin{array}{l}\text { Parity } \\
\text { Nulliparous } \\
\text { Multipara }\end{array}$ & $\begin{array}{c}5 \\
45\end{array}$ & $\begin{array}{l}10.0 \\
90.0\end{array}$ & $\begin{array}{l}15 \\
35\end{array}$ & $\begin{array}{l}30.0 \\
70.0\end{array}$ & $\begin{array}{l}18 \\
32\end{array}$ & $\begin{array}{l}36.0 \\
64.0\end{array}$ & $\begin{array}{c}07.411 \\
P>0.05\end{array}$ \\
\hline $\begin{array}{l}\text { Mode of delivery } \\
\text { Normal vaginal delivery } \\
\text { Without episiotomy } \\
\text { With episiotomy } \\
\text { Cesarean section } \\
\text { Emergency (selective) } \\
\text { Planned (elective) }\end{array}$ & $\begin{array}{l}12 \\
10\end{array}$ & $\begin{array}{l}24.0 \\
20.0 \\
\\
28.0 \\
28.0 \\
\end{array}$ & $\begin{array}{l}15 \\
16 \\
\end{array}$ & $\begin{array}{l}16.0 \\
22.0 \\
\\
30.0 \\
32.0 \\
\end{array}$ & $\begin{array}{c}9 \\
13\end{array}$ & $\begin{array}{l}18.0 \\
26.0 \\
\\
20.0 \\
36.0\end{array}$ & $\begin{array}{c}0.241 \\
P>0.05\end{array}$ \\
\hline
\end{tabular}

$\chi^{2}$ : Chi-Square test: Statistically significant at $\mathrm{p} \leq 0.05$

Table 2. Distribution of the studied neonates sample according to their general characteristics ( $n=50$ each group)

\begin{tabular}{|c|c|c|c|c|}
\hline Variables & $\begin{array}{l}\text { Human milk } \\
\text { (group 1) }\end{array}$ & $\begin{array}{l}\text { Alcohol 70\% } \\
\text { (group 2) }\end{array}$ & $\begin{array}{c}\text { Povidine iodine 10\% } \\
\text { (group 3) }\end{array}$ & $\begin{array}{c}\text { Test } \\
\text { p value }\end{array}$ \\
\hline $\begin{array}{l}\text { Gestational age (in weeks) } \\
\text { Mean } \pm \mathrm{SD}\end{array}$ & $38.61 \pm 1.31$ & $38.58 \pm 1.30$ & $37.88 \pm 1.29$ & $\mathrm{P}>0.05$ \\
\hline $\begin{array}{l}\text { Sex of newborn } \\
\text { Male } \\
\text { Female }\end{array}$ & $\begin{array}{l}32.0 \\
68.0\end{array}$ & $\begin{array}{l}58.0 \\
42.0\end{array}$ & $\begin{array}{l}38.0 \\
62.0\end{array}$ & $\begin{array}{l}\chi^{2}=54 \\
p>0.05\end{array}$ \\
\hline $\begin{array}{l}\text { Birth weight in grams } \\
\text { Min-Max } \\
\text { Mean } \pm \text { SD }\end{array}$ & $\begin{aligned} & 2.850-3.750 \\
& 3261.5 \pm 149.10 \\
&\end{aligned}$ & $\begin{array}{c}2.850-3.850 \\
3255.38 \pm 137.19 \\
\end{array}$ & $\begin{array}{c}2.990-3.950 \\
3265.38 \pm 127.10 \\
\end{array}$ & $\begin{array}{c}\text { t-test } \\
p>0.05\end{array}$ \\
\hline $\begin{array}{l}\text { Apgar score }>7 \\
\text { Mean } \pm \mathrm{SD} \\
\text { At } 1 \text { minute } \\
\text { At } 5 \text { minutes }\end{array}$ & $\begin{array}{l}8.8 \pm 1.35 \\
9.2 \pm 1.39\end{array}$ & $\begin{array}{c}7.6 \pm 1.57 \\
7.33 \pm 1.57\end{array}$ & $\begin{array}{c}7.9 \pm 1.42 \\
8.13 \pm 1.45\end{array}$ & $P>0.05$ \\
\hline
\end{tabular}

$\chi^{2}$ : Chi-Square test *: Statistically significant at $\mathrm{p} \leq 0.05$ 


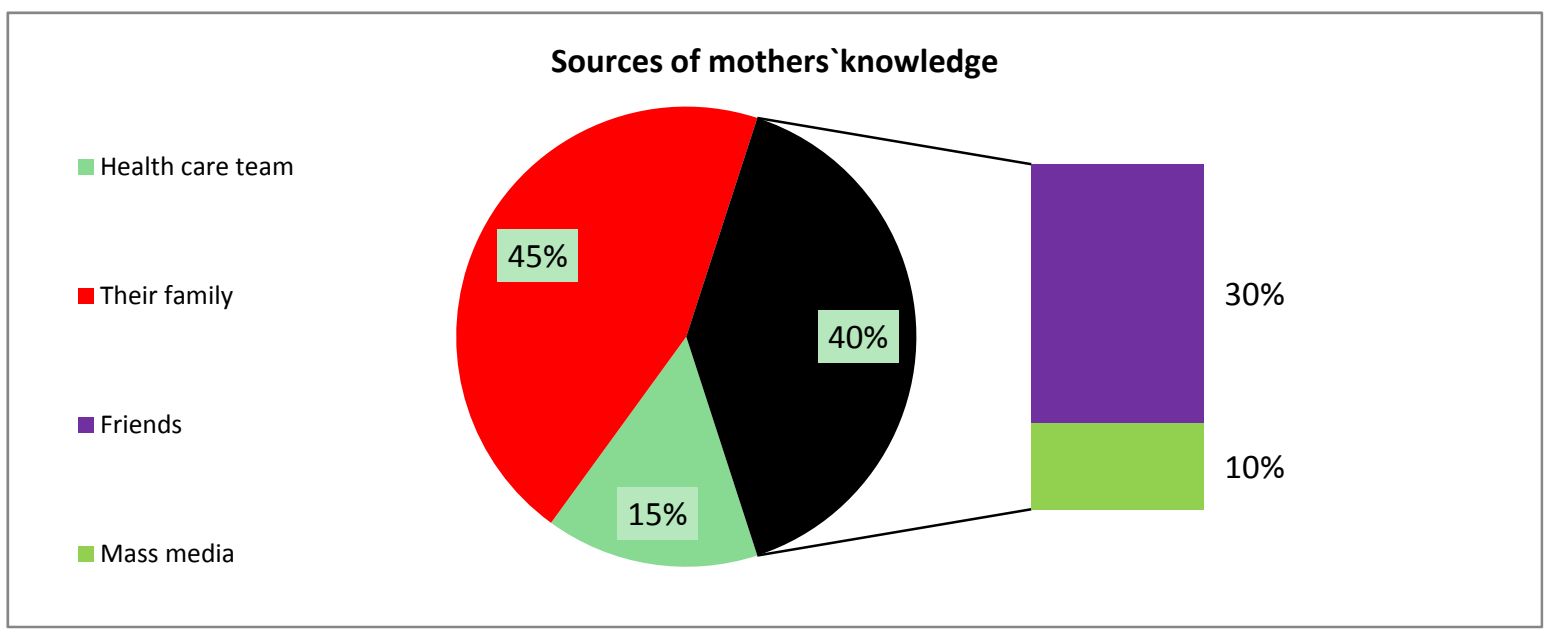

Figure 1. Distribution of mothers regarding their source of information about umbilical cord cleansing $(n=150)$

Table 3. Mothers' satisfactory knowledge about umbilical cord cleansing pre/post implementation of the educational program (each group $\mathrm{n}=50$ )

\begin{tabular}{|c|c|c|c|c|c|c|c|c|c|c|c|}
\hline \multirow{3}{*}{$\begin{array}{l}\text { Knowledge } \\
\text { about } \\
\text { Umbilical Cord } \\
\text { Cleansing }\end{array}$} & \multicolumn{9}{|c|}{ Mothers' satisfactory knowledge } & \multirow{3}{*}{$\begin{array}{c}\chi^{2} \\
\text { test }\end{array}$} & \multirow{3}{*}{ P -value } \\
\hline & \multicolumn{3}{|c|}{$\begin{array}{l}\text { Human milk } \\
\text { (group 1) }\end{array}$} & \multicolumn{3}{|c|}{$\begin{array}{l}\text { Alcohol 70\% } \\
\text { (group 2) }\end{array}$} & \multicolumn{3}{|c|}{$\begin{array}{l}\text { Povidine-iodine } 10 \% \\
\text { (group 3) }\end{array}$} & & \\
\hline & Pre & Post & $\begin{array}{l}\text { Follo } \\
\text { w up }\end{array}$ & Pre & Post & $\begin{array}{l}\text { Foll } \\
\text { ow } \\
\text { up }\end{array}$ & Pre & Post & $\begin{array}{l}\text { Follow } \\
\text { up }\end{array}$ & & \\
\hline $\begin{array}{l}\text { Definition of } \\
\text { typical cord } \\
\text { care }\end{array}$ & 20.0 & 98.0 & 96.0 & 15.0 & 94.0 & 92.0 & 27.0 & 96.0 & 90.5 & 339.41 & $<0.001 *$ \\
\hline $\begin{array}{l}\text { Factors } \\
\text { affecting on } \\
\text { cord healing }\end{array}$ & 15.0 & 95.0 & 92.0 & 18.0 & 97.0 & 94.0 & 22.0 & 98.0 & 93.0 & 343.29 & $<0.001^{*}$ \\
\hline $\begin{array}{l}\text { Method and } \\
\text { material for } \\
\text { securing } \\
\text { umbilical cord }\end{array}$ & 30.0 & 97.0 & 95.0 & 35.0 & 92.0 & 90.0 & 33.0 & 93.0 & 86.0 & 354.33 & $<0.001 *$ \\
\hline $\begin{array}{l}\text { Solution used } \\
\text { for cleaning } \\
\text { cord }\end{array}$ & 17.0 & 97.0 & 94.0 & 15.0 & 94.0 & 91.0 & 20.0 & 90.0 & 86.0 & 380.26 & $<0.001^{*}$ \\
\hline $\begin{array}{l}\text { Time of } \\
\text { separation }\end{array}$ & 45.6 & 98.0 & 95.0 & 30.0 & 92.0 & 90.0 & 32.0 & 95.0 & 91.0 & 368.6 & $<0.001 *$ \\
\hline $\begin{array}{l}\text { Signs of } \\
\text { inflammation }\end{array}$ & 30.5 & 93.0 & 90.0 & 19.0 & 90.0 & 87.0 & 26.0 & 96.0 & 92.3 & 331.77 & $<0.001 *$ \\
\hline $\begin{array}{l}\text { Umbilical cord } \\
\text { care benefits }\end{array}$ & 28.0 & 98.0 & 95.0 & 25.0 & 97.0 & 93.0 & 29.0 & 92.0 & 89.0 & 317.13 & $<0.001 *$ \\
\hline Mean \pm SD & $25.2 \pm$ & & & $92.7 \pm$ & & & 84.1 & 2.9 & & & $<0.001 *$ \\
\hline
\end{tabular}

$\chi^{2}$ : Chi-Square test $*$ Significant $\mathrm{P} \leq 0.05$ 


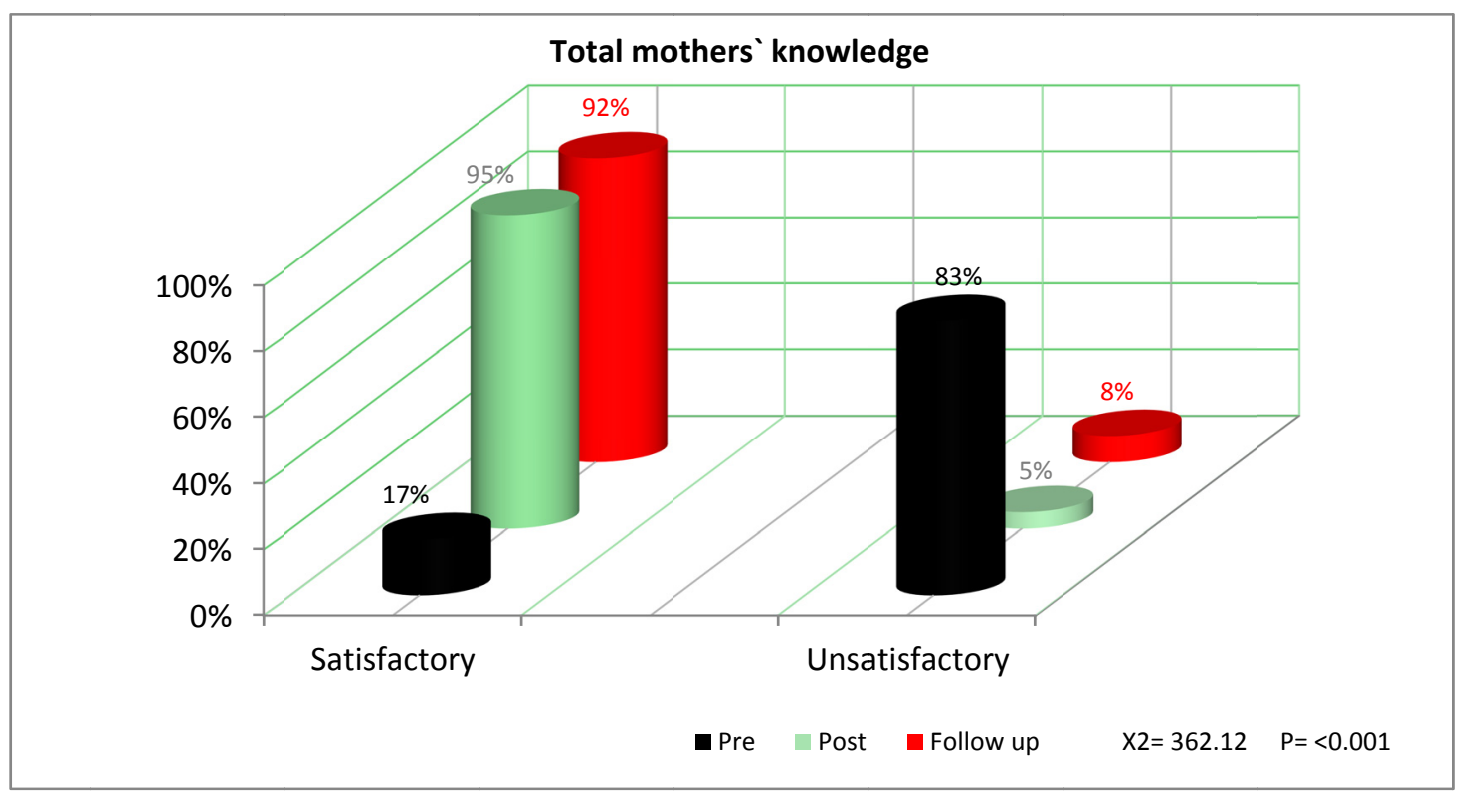

Figure 2. Mothers' satisfactory total knowledge score about umbilical cord cleansing pre/post implementation of the educational program (each group $\mathrm{n}=50$ )

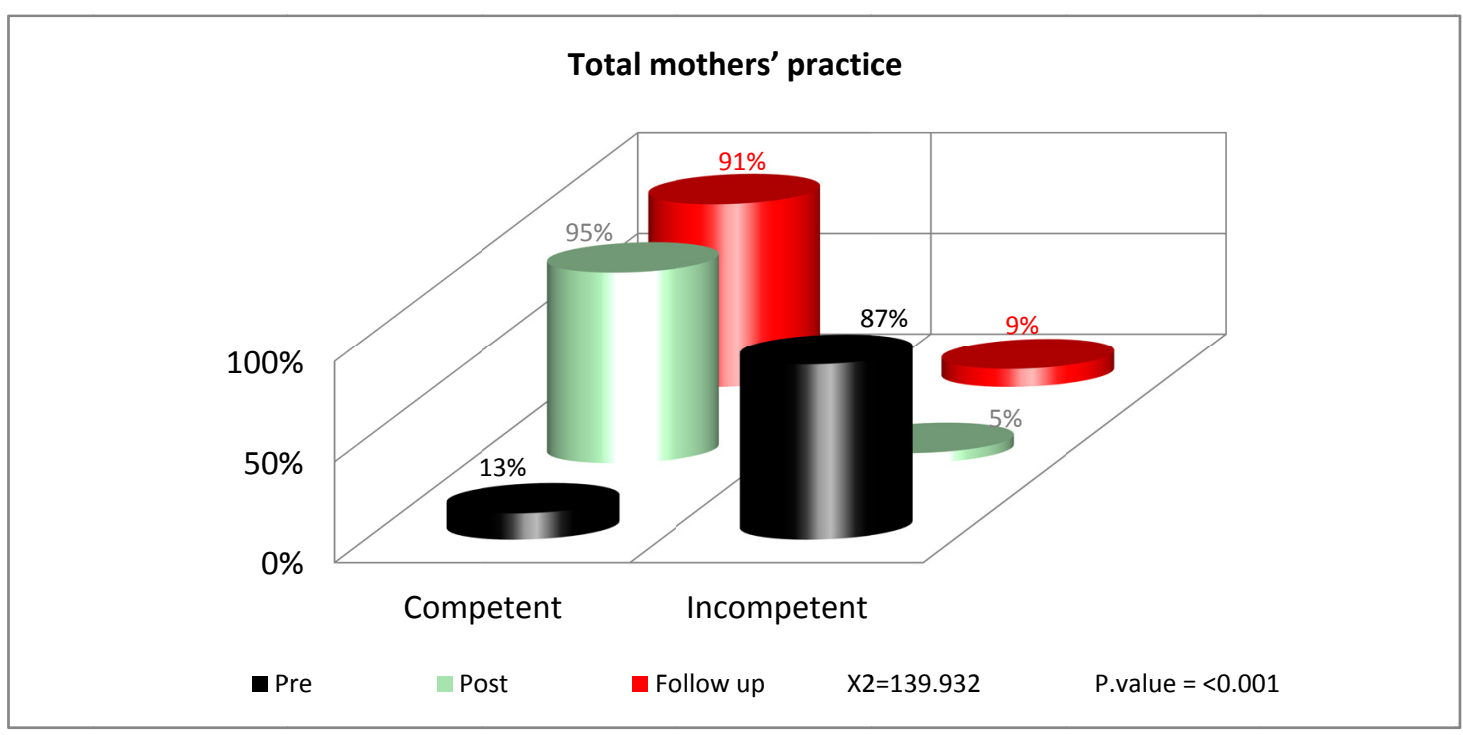

Figure 3. Mothers' satisfactory total practice about umbilical cord cleansing pre/post implementation of the educational program (each group $\mathrm{n}=50$ )

Table 4. Distribution of the studied sample according to the cord separation time per days (each group $n=50$ )

\begin{tabular}{|c|c|c|c|c|c|c|c|c|}
\hline \multirow{2}{*}{$\begin{array}{l}\text { Umbilical Cord separation } \\
\text { time (in days) } \\
<7 \text { days }\end{array}$} & \multicolumn{2}{|c|}{$\begin{array}{l}\text { Human milk } \\
\text { (group 1) }\end{array}$} & \multicolumn{2}{|c|}{$\begin{array}{l}\text { Alcohol 70\% } \\
\text { (group 2) }\end{array}$} & \multicolumn{2}{|c|}{$\begin{array}{l}\text { Povidine-iodine } \\
10 \% \text { (group 3) }\end{array}$} & \multirow{4}{*}{$\begin{array}{l}\text { Test } \\
\chi^{2} \\
12.44\end{array}$} & \multirow{3}{*}{$\begin{array}{l}\text { p value } \\
0.001 *\end{array}$} \\
\hline & 45 & 90.0 & 5 & 10.0 & 2 & 4.0 & & \\
\hline $7-10$ days & 5 & 10.0 & 18 & 36.0 & 13 & 26.0 & & \\
\hline$>10$ & 0 & 0.0 & 27 & 54.0 & 35 & 70.0 & & \\
\hline Mean \pm SD & \multicolumn{2}{|c|}{$4.72 \pm 0.71$} & \multicolumn{2}{|c|}{$8.32 \pm 1.14$} & \multicolumn{2}{|c|}{$9.91 \pm 1.84$} & & 0.001* \\
\hline
\end{tabular}

$\chi^{2}$ : Chi-Square test; ANOVA test: A statistical significant difference $(\mathrm{P} \leq 0.05)$ 


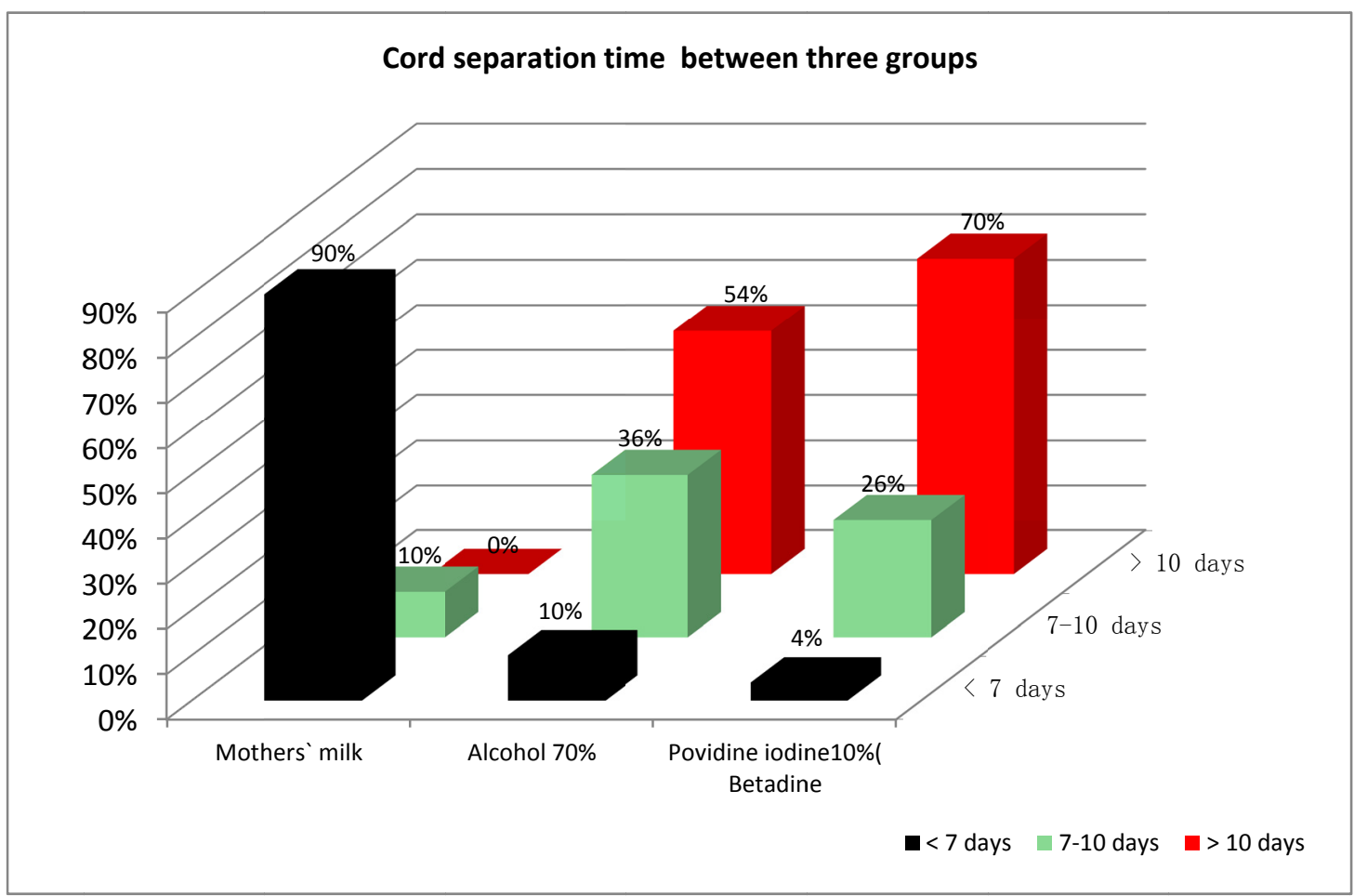

Figure 4. Distribution of the studied sample according to the cord separation time per days (each group $n=50$ )

Table 5. Distribution of the studied neonates sample according to signs of cord infection in the first and the second visit (each group $\mathrm{n}=50$ )

\begin{tabular}{|c|c|c|c|c|c|c|c|c|}
\hline \multirow[b]{2}{*}{ Variable } & \multicolumn{3}{|c|}{ First visit ( 4th day) } & \multirow[b]{2}{*}{$P$ value } & \multicolumn{3}{|c|}{ Second visit (8th day) } & \multirow[b]{2}{*}{ P value } \\
\hline & $\begin{array}{c}\text { group } \\
1\end{array}$ & $\underset{2}{\operatorname{group}}$ & $\begin{array}{c}\text { group } \\
3\end{array}$ & & $\underset{1}{\operatorname{group}}$ & $\underset{2}{\text { group }}$ & $\underset{3}{\text { group }}$ & \\
\hline High body temperature & 0.0 & 0.0 & 0.0 & $>0.005$ & 0.0 & 4.0 & 8.0 & $<0.001 *$ \\
\hline Warmth and mild redness & 18.0 & 30.0 & 48.0 & $<0.001^{*}$ & 0.0 & 12.0 & 18.0 & $<0.001$ \\
\hline Moderate or severe redness & 0.0 & 1.0 & 4.0 & $<0.001^{*}$ & 0.0 & 8.0 & 16.0 & $<0.001$ \\
\hline Severe redness with pus & 0.0 & 0.0 & 0.0 & $>0.005$ & 0.0 & 10.0 & 10.0 & $<0.001$ \\
\hline Foul odor of cord & 0.0 & 0.0 & 0.0 & $>0.005$ & 0.0 & 6.0 & 10.0 & $<0.001$ \\
\hline Cord exudate & 0.0 & 0.0 & 0.0 & $>0.005$ & 0.0 & 12.0 & 14.0 & $<0.001$ \\
\hline Abnormal color of the skin & 0.0 & 0.0 & 0.0 & $>0.005$ & 0.0 & 16.0 & 20.0 & $<0.001$ \\
\hline
\end{tabular}

$\chi^{2}$ : Chi-Square test: A statistical significant difference $(\mathrm{P} \leq 0.05)$

Table 6. Mean scores of cord-bleeding continuations among the three groups of umbilical cord cleansing (each group $\mathrm{n}=50$ )

\begin{tabular}{|lcccc}
\hline Variable & $\begin{array}{c}\text { Human milk } \\
\text { (group 1) }\end{array}$ & $\begin{array}{c}\text { Alcohol 70\% } \\
\text { (group 2) }\end{array}$ & $\begin{array}{c}\text { Povidine-iodine 10\% } \\
\text { (group 3) }\end{array}$ & P value \\
\hline $\begin{array}{l}\text { Bleeding continuation after } \\
\text { separation (day) }(\text { Mean } \pm \text { SD) }\end{array}$ & $1.34 \pm 0.60$ & $2.54 \pm 0.69$ & $3.46 \pm 0.81$ & $<\mathbf{0 . 0 0 1 *}$ \\
\hline
\end{tabular}

\section{Discussion}

However, caring for the neonatal umbilical cord stump is very important; immediately and after childbirth, 
various researches focused on cord care; more often on managements as clamping time for cord and the use of local antimicrobials on the cord stump and few researchers focused have been to methods that are natural or cultural. Some mothers using traditional practices for umbilical cord cleansing for their neonates. The researchers found few studies in the topic of research. Umbilical-cord-separation, normally, occurs within 10-14 days after birth. The delayed fall-out may be associated with different types of microbial infection (Broom, 2012). Consequently, in the present study, the researchers attempted to study the impact of an educational program of mothers' knowledge and practice about umbilical cord cleansing. Moreover, the researchers attempted to monitor and compare the effect of topical application of human-breast-milk, alcohol $70.0 \%$, and povidine-iodine $10.0 \%$ on clinical outcomes and separation time of umbilical cord stump among healthy neonates.

In the current study, there were no statistically significant differences between all studied groups in their general/socio-demographic/obstetrical characteristics of the participated mothers. This indicates that all groups were homogeneous prior to the study conducting. In the present study, the mean age of the studied mother in the three groups was found to be around the twenties and the most of studied sample hadn't completed their high-education and were illiterate, primary or secondary school graduates, housewives, and rural dwellers. This could explain, the pre-program, poor/unsatisfactory score of mothers' knowledge and practices regarding umbilical cord care. This study result was supported by Elsobky, et al., (2017) study "effect of topical application of mother milk on umbilical cord stump separation time compared to ethanol in healthy newborn", who found in their results that the mothers in both studied groups, predominately, were in their twenties, can read \& write or secondary school graduates, and, housewives. Similarly, Abbaszadeh, et al (2016) who compared the impact of the topical application of human milk and chlorhexidine on cord separation time in newborns and found that the mean age of the mothers was $27.20 \pm 5.14$ years and approximately $35.0 \%$ of mothers hadn't completed their high-education. However, Eraky \& Hassan (2018) indicated that there was no statistically significant relationship between postnatal mother`s residence, educational level and total mean score of practice, however, more than half of the study sample in the middle age (20-25) and there was a significant relation between mother`s age and total mean score of practice.

Likewise, there was no significant statistical difference was found among all groups in neonates' characteristics. This indicated that neonates' characteristics in all groups were homogenous before the conduction of the study. In the same way (Aghamohammadi et, al., 2012) found in their conducted study "comparing the effect of topical application of human milk and dry cord care on umbilical cord separation time in healthy newborn infants" that there were no significant statistical differences between the two studied groups in newborns' sex, birth weight, gestational age, type of delivery, and maternal age.

As regards mothers' source of information about umbilical cord care and its cleansing technique, this study results revealed that, mothers' family were the main source of their information for around half $(45.0 \%)$ of studied mothers, followed by their friend (30.0\%), while only $15.0 \%$ the of mothers obtained their knowledge from health care team. This could explain the poor knowledge and incompetent practices of the participating mothers regarding umbilical cord care. This may be attributed to that a presentable percentages of the studied sample were rural dwellers that their culture attempts to fear on the newborn from vision. This point-of-view is in-accordance with may researchers, who stated that; in close community families and many cultures, they attempt to hidden their neonates and applies some substances to the cord stump and are associated with high risk of infection (Zupan, 2004 ; sinah et al., 2015); as ashes, oil, butter, spice pastes, herbs and mud (Adebami, 2014). This is contradicted the result of a study conducted by Amolo, et al. (2017) in Kenya, which denote that (95.4\%) of the participated women in their study received antenatal/postnatal care from a medical professional, either from nurses and midwives $(64.3 \%)$ or doctors (31.1\%). The strangeness of the results may be implying that mothers in those setting rely predominantly on health care providers for information on neonates care rather than family and peers.

These results agreed with Susan \& Achora (2012) who assessed knowledge and practice for mothers at postnatal period for the care of umbilical cord stump and convey that the knowledge on postnatal period cord care continuity dependent on who caring for the cord stump, the good knowledge was present by the mothers who were assisted by the students on midwifery experiment. So, for this reason, it is important to approach the subject, so that health education programs and guidelines could bring significant improvement in their knowledge and practice about umbilical-cord-cleansing. After the implementation of educational program phases (post and follow-up) knowledge and practices of these mothers had enhanced, this result is in agreement with Kudachi et al. (2017) who evaluated the impact of health education on knowledge of newborn care in India and reported that knowledge of newborn care as eye care, cord care, breastfeeding among primigravida women improved significantly after providing health education.

The first section in the present study discussed the $1^{\text {st }}$ hypothesis that studied the effect of implementation of an 
educational program on mothers' knowledge and competency of their practice about umbilical cord cleansing technique, regardless of the liquid used for cleansing. The results of the study declare that the majority (83.0\%) of the mothers in all studied groups had an unsatisfactory level of baseline knowledge about cord care as presented in figure 2. Moreover, the results portrayed in figure 3 illustrated mothers' total practice score about umbilical cord cleansing; it revealed that the majority of the studied mothers $(87.0 \%)$ had incompetent practices regarding umbilical cord care. This finding is in inconsistency with a study done in Iran (Reza , 2013). It had found that 78.5\% had moderate, $13.3 \%$ had a good \& $8.2 \%$ had poor knowledge regarding newborn care. Another study was done by Castalino et al. (2014) stated that the majority of mothers had good knowledge concerning cord care.

Maintaining and expanding correct knowledge regarding obstetrical and related neonatal issues is the main responsibility of midwife as well as maternity and neonatal health nurses, who play a critical role in antenatal/postnatal units in driving continuous improvement in maternal and neonates' health outcomes, which in-turn increase women's self-reliance, their ability to make health decisions and to seek better health care. Slightly around one-third of mothers in the three studied groups at the present study had a secondary educational level; this can help for women cooperation, accepting and practicing the procedure (Zahra, 2018; Mohamed, 2019; Sheha et al., 2018; Said et al., 2018; Eid et al, 2019). As the researchers affiliated to pediatric, maternity and newborn health nursing branch, therefore, they played a vital role in antenatal/postnatal units in providing women with a clear and adequate knowledge as well as competent practices regarding umbilical cord care. They encourage them to ask their questions and re-demonstrate the applied procedure to get their need information and competency to enhance their performance. Educating the clients is a role for nurses in all health care settings; the nurse is often the main source of information about health promotion that is why they have a very important role in the current educational guidelines (Nasr, 2016; Abd-Allah et al., 2017; Hassan, 2019). Therefore, this program aimed to increase mothers' awareness regarding umbilical cord care.

Regarding the effect of the implemented program for umbilical cord care, the results of the present study declare an improvement of mother's knowledge in allover items (definition of typical cord care, factors affecting on cord healing, method and material for securing umbilical cord, solution used for cleaning cord, time of separation, signs of inflammation, umbilical cord care benefits) with a highly significant relation $(p<0.001)$ for all items. Moreover, the results revealed, also, progress and improvement in mothers' competency of cord care procedure regardless of the used solution. Figure 3 illustrates that the majority of studied mothers (95.0\%) had a competent performance for cord care procedure, with a highly statistically significant difference $(p<0.001)$; this improvement reflects the impact of the implemented program. The progress of knowledge's score may be attributed to wide varieties of educational methods used by the researcher as audiovisual materials, pamphlets, lectures, videos, and demonstration and re-demonstration as well as Arabic booklet (Hassan et al., 2017). This is in accordance with Edgar Dale's or the NTL's Pyramid of Learning as cited by many authors as the pyramid illustrated that individuals can retain $50.0 \%$ of what he demonstrates (see and hear), $30.0 \%$ of what he watches (video and image), $20.0 \%$ of what he hear, and $10.0 \%$ of what he read (Hassan, 2018; Hassanine, 2017; Hassan \& Nasr, 2017). In the same line, the National Training Laboratories Institute has found that ones can retain $30.0 \%$ of what he learned by demonstration and $75.0 \%$ by Practice by doing (Kumar, 2007).

Also, the results revealed that, a highly statistically significant difference has been found between mean scores of mothers' total knowledge and mothers' practice in the intervention of educational program groups pre/immediate-post/follow-up $(\mathrm{p}<0.001)$ in the all studied groups. These findings are matched with studies done by Shrestha et al. (2013) \& Mohamed, (2018) who studied knowledge and practice of postnatal mother on newborn care and reported poor cord care practices before the intervention and great improvement after intervention and the effect of umbilical cord care interventional program on mothers' performance and occurrence of cord problems among their newborn infants, respectively. This statistically significant improvement was found between mean scores of mothers' practices in intervention group pre/immediate-post/follow-up posttest of the intervention related to cord care, while mothers in control group had no improvement in their practice through phases of the intervention program (pre/immediate-post/follow-up posttests). Therefore, the researchers recommend to improve newborn survival, newborn care should be integrated into the recent maternal and child interventions, and should be implemented at both community and health facility level as part of a universal coverage strategy.

The second section in the present study discussed the $2^{\text {nd }}$ hypothesis that studied the clinical outcome of umbilical cord of the healthy newborn (cord separation time, signs of umbilical cord infection and bleeding continuation after separation) among babies whose mothers used human-breast-milk for cord cleansing versus other groups who used alcohol $70.0 \%$ and povidine-iodine $10.0 \%$.

Firstly, infection signs (fever, warmth, redness, pus, foul odor of cord, and cord exudate) were almost 
non-existent in all groups in the $1^{\text {st }}$ visit $\left(4^{\text {th }}\right.$ day); which indicated the effectiveness and proper technique of umbilical cord care regardless the used antiseptic solution. While in $2^{\text {nd }}$ visit $\left(8^{\text {th }}\right.$ day), infection signs were completely non-existent in group 1 whose mothers used breast milk for caring and cleaning umbilical cord. All signs of cord-infection were apparent in other both groups whose mothers used alcohol $70.0 \%$ and povidine-iodine $10.0 \%$; however, these signs were more pre-existing in group 3 whose mothers used povidine-iodine $10.0 \%$. Significant differences were found between all groups regarding all items of signs of infection; this is indicated that breast milk is considered the best of choice for caring and cleaning neonates' umbilical cord. This may be attributed to; mother milk can be effective more than alcohol and povidine iodine (broad-spectrum antibiotics) in reducing signs of infection of cord. Colostrum contains a vast amount of natural-antimicrobial-agents which provides specific/nonspecific passive immunity to the newborns (Abbaszadeh et al., 2014). Human-milk contains large amounts of IgA antibodies which improve the immunity of neonates (Allam et al., 2015). A similar observation in the study reported by Elsobky, et al., (2017) who found that there was a significant difference with little infection in mother milk group than the ethanol group in their study. But these findings disagreed with Abbaszadeh, et al., (2016) who reported no significant correlation between signs of infection (discharge, redness, and swelling) in their both groups. No cases of granuloma formation and sepsis were found in their study and none of the neonates needed to be hospitalized. Additionally, Azzam etal., (2011) found that no statistically significant difference between their studied groups, the neonates in the alcohol cord care group had more redness around their umbilical-cord-stump.

Secondly, As regards the mean score of cord separation time and bleeding continuation in mother milk, alcohol $70.0 \%$ and povidine-iodine $10.0 \%$ groups; the existing study reported that earlier cord separation in newborns whose mothers used breast milk (Mean $\pm \mathrm{SD} ; 4.72 \pm 0.71$ ) than other ones in alcohol (Mean $\pm \mathrm{SD} ; 8.32 \pm 1.14$ ) and povidine-iodine (Mean $\pm \mathrm{SD} ; 9.91 \pm 1.84$ ) groups, respectively. A statistically significant difference between all groups was observed $(\mathrm{p}<0.001)$. Additionally, less bleeding continuation in breast milk (Mean $\pm \mathrm{SD} ; 1.34 \pm$ 0.60 ) than in alcohol $70.0 \%$ (Mean $\pm \mathrm{SD} ; 2.54 \pm 0.69$ ) and povidine-iodine $10.0 \%$ groups (Mean $\pm \mathrm{SD} ; 3.46 \pm$ $0.81)$ associated with statistically significant difference between all groups $(\mathrm{p}<0.001)$ were observed. This may be due to the effect of human breast milk in umbilical-cord-separation. Human breast milk has many immunologic and disinfecting influences and is the best nourishment source for newborns and reduced bacterial colonization and leukocytes secretion, which were essential for umbilical cord separation (Abd-Allah et al., 2017). Human breast milk can promote and repair the growth of the musculoskeletal system which will enhance development and increase the amount of polymorph nuclear leukocytes and other immunologic factors which can increase fetal immunity and in-turn decrease the process of cord separation (Abbaszadeh et al., 2014). Human-breast-milk with its antimicrobial properties can act as an adequate defensive agent which can protect the cord from getting any infection, as the newborns have no protective flora at birth. Moreover, breast milk, also, having influence over falling of umbilical cord causing early separation, thereby, decreasing the exposure to the external environment resulting in lessens chances of infection. (Aghamohammadi et al., 2012). This study is supported by Golshan \& Hossein, (2013) in their study about the impact of ethanol, dry care and human milk on the time for umbilical cord separation; they found that the mean time for umbilical cord separation had significant difference among the three studied groups. Umbilical separation time in neonates of the human milk group had significant differences with the other two groups. A similar observation in the study reported by Farahani, et a.l, (2008) and Ahmadpour-Kacho et al., (2006) who found that the mean time for umbilical cord separation in the human-milk-group was significantly lower than the other studied groups, and increased, respectively, in alcohol, drying and silver sulfadiazine groups. Contradictly, Azzam et al., (2011) who examined the effect of topical application of alcohol $70.0 \%$ on umbilical cord-stump-separation-time, found that found that the falling-out time of umbilical-cord-stump occurs within one-week (Mean $\pm \mathrm{SD} ; 6.70 \pm 1.03$ days).

In this view, the current study declared that the duration of the umbilical cord stump separation time among neonates whose mothers used breast milk for cord care is shorter than in the other groups who used alcohol $70.0 \%$ and povidine-iodine $10.0 \%$ by about $4-5$ days. In spite, the umbilical cords were detached in each group among the traditional amount between (1-2 weeks following the birth) as documented in the literature. The lowest and the highest separation times, respectively, belonged to human milk and povidine iodine $10.0 \%$ groups, respectively, is in accordance with the study done by Dhanawade (2014) who reported that the total mean score of breast milk application group after the intervention was 5.22 and in control group 9.36. The research hypothesis $(\mathrm{H} 2)$ was accepted as the application of breast milk is highly effective in the early separation of cord stump. Lastly, Educational program had a positive effect on mothers' knowledge and competency of their practice regarding umbilical cord cleansing. In this respect, hypothesis (H1) was also accepted. 


\section{Conclusion}

It is clear from the results that the study hypotheses were accepted and supported where the implemented program played a critical role in improving maternal knowledge and competency of their practices regarding umbilical cord care which in-turn affected neonates' health outcomes. Mother's breast milk scored the shorter neonates' cord-base-separation-time and best healing associated with lesser infection as well as lesser bleeding than alcohol $70.0 \%$ and povidine-iodine $10.0 \%$; this is indicated that breast milk is considered the best of choice for caring and cleaning neonates' umbilical cord.

\section{Recommendation}

1. Implement mother-classes for expectant mothers during their antenatal visits in their third trimester to improve and enhances their knowledge and competency of neonates' umbilical-cord-care procedure.

2. Dissemination the results of the research in antenatal clinics to encourage breast milk usage for neonates' umbilical cord care.

3. Further studies can be replicated on a large sample size with longer duration in different settings so that the results can be generalized to a large population.

4. Further researches need to study the effect of newborn cord care practices on the prevalence of neonates' morbidity.

\section{References}

Abbaszadeh, F., Hajizadeh, Z., \& Jahangiri, M. (2016). Comparing the impact of the topical application of human milk and chlorhexidine on cord separation time in newborns. Pak J Med Sci., 32(1), 239-243. http://dx.doi.org/10.12669/pjms.321.8223

Abbaszadeh, F., Hajizadeh, Z., Atrian, M., Bagheri, A., \& Sarafraz, N. (2014). Comparison of the effect of topical application of human milk and dry cord care on the bacterial colonization of umbilical cord in newborn infants. J Kermanshah Univ Med Sci., 18, 1-8.

Abd-Allah, N., Nasr, E., \& Hassan, H. (2017). Impact of a Breast-Feeding Educational Program for Mothers Having Pre-Term Infants in General Hospitals in Port Said. International Journal of Novel Research in Healthcare and Nursing, 4(3), 215-225.

Adebami, O. (2014). Evaluation of home care management of umbilical cord stumps by mothers at Ilesa, Southwestern Nigeria. Niger J Paed., 41(3), 218-222.

Aghamohammadi, A., Zafari, M., \& Moslemi, L. (2012). Comparing the Effect of Topical Application of Human Milk and Dry Cord Care on Umbilical Cord Separation Time in Healthy Newborn Infants. Iran J Pediatr., 22(2), 158-162.

Ahmadpour-Kacho, M., Zahedpasha, Y., Hajian, K., Javadi, J., \& Talebian, H. (2006). The effect of topical application of human milk, Ethyl alcohol $96 \%$ and silver sulfadiazine on umbilical cord separation time in newborn infant. Arch Iranian Med., 9, 33-8.

Allam, N., Al Megren, W., \& Talat, A. (2015). The effect of topical application of mother milk on separation of umbilical cord for newborn babies. Am J Nurs Sci., 4, 288-96.

Amolo, L., Irimu, G., \& Njai, D. (2017). Knowledge of postnatal mothers on essential newborn care practices at the Kenyatta National Hospital: a cross sectional study. Pan Afr Med J., 28, 97.

Azzam, H., Abd El Hamid, A., \& Abd El Fadil, N. (2011). Effect of topical application of alcohol 70\% versus distilled water on umbilical cord stump separation time and bacterial colonization among neonates at El Manial Maternity Hospital-Cairo University: randomized control trial. Egyptian Nursing Journal, 1(2), 2090-6021.

Broom, M., \& Smith, S. (2012). Late Presentation of Neonatal Omphalitis Following Dry Cord, Care. Clinical Pediatrics, 52(7), 675-677.

Castalino, F., Nayak, B., \& D'souza, A. (2014). Knowledge and Practices of postnatal mothers on new-born care in tertiary care hospital of Udupi district. NUJHS, 4, 2-8.

Chawla, G., \& Diwaka, K. (2015). Comparison of Umbilical Cord Cleansing Using Sterile Water and Povidine Iodine-Spirit During Early Neonatal Period: A Double-Blind Randomized Control Trial. J Clin Diagn Res., 9(7), SC01-SC03.

Daiahunlin, L., Sukhjit, K., Praveen, K., Vikas, G., \& Sandhya, G. (2017). Effect of Topical Application of 
Human Breast Milk Versus 4\% Chlorhexidine Versus Dry Cord Care on Bacterial Colonization and Clinical Outcomes of Umbilical Cord in Preterm Newborns. Acad J Ped Neonatol, 6(1), 555-730.

Dhanawade, R. (2014). Innovations in Pharmaceuticals and Pharmacotherapy. IPP., 2(3), 386-394.

Eid, S., Hassan, H., Fathy, W., \& Abou-Shabana, K. (2019). Study Women Verbal and Nonverbal Response, During Their First Gynecological Examination. American Journal of Nursing Research, 7(1), 1-7.

Elsobky, F., Emam, A., Abd Elmenim, S., \& Shahin, M. (2017). Effect of Topical Application of Mother Milk on Umbilical Cord Stump Separation Time Compared To Ethanol in Healthy Newborn.

Eraky, E., \& Hassan, E. (2018). Effect of Newborn-care Practices for Postnatal Mothers on Occurrence of Selected Health Problems among Their Newborn Infants. American Journal of Nursing Research, 6(4), 174-182.

Farahani, L., Mohammadzaeh, A., Taffazzoli, M., Esmaeli, H., \& Ghazvini K. (2008). Effect of topical application of breast milk and dry cord care on bacterial colonization and umbilical cord separation time in neonates. Journal of Chinese Clinical Medicine, 3(6), 327-332.

Farg, D., \& Hassan, H. (2019). Study Hyperemesis Graviderum Requiring Hospital Admission during Pregnancy: Effect of Nursing Implication on Its Progress. American Journal of Nursing Research, 7(3), 328-341.

Golshan, M., \& Hossein, N. (2013). Impact of ethanol, dry care and human milk on the time for umbilical cord separation. J Pak Med Assoc., 63(9), 1117-1119.

Hassan, H. (2018). Effectiveness of a structured teaching program on anxiety and perception regarding toxoplasmosis among seropositive pregnant women in Northern Upper Egypt. Clinical Nursing Studies, 6(1), 1-19.

Hassan, H., \& Nasr, E. (2017). Improving nurses' knowledge and skills regarding tocolytics for inhibiting preterm labor. Clinical Nursing Studies, 5(1), 1-12. https://doi.org/10.5430/cns.v5n1p1

Hassan, H., Gamel, W., Sheha, E., Sayed, M., \& Arafa, A. (2019). Menstrual disorders necessitating counseling among students in Beni-Suef University. Clinical Nursing Studies, 7(2), 29-36.

Hassan, H., Mohamady, Sh., \& Abd El-Gawad, N. (2017). Protocol for improving nursing performance towards placental examination at labor units. Clinical Nursing Studies, 5(2), 1-11. http://dx.doi.org/10.5430/cns.v5n2p1

Hassanine, Sh., Hassan, H., \& Alkotb, Z. (2017). Effect of Preventive Program on Progression of Osteoporosis among Female Patients over 40 years at El-Fayoum City. American Research Journal of Nursing, 3(1), $1-15$.

Karumbi, J., Mulaku, M., Aluvaala, J., Mike, E., \& Opiyo, N. (2013). Topical Umbilical Cord Care for Prevention of Infection and Neonatal Mortality. The Pediatric Infectious Disease Journal, 32(1), 78-83.

Kudachi, P., Prabhu, M., \& Angolkar, B. (2017). Impact of health education on knowledge of newborn care among expectant women in urban area of Belagavi, India: pre and post study. International Journal of Contemporary Medical Research, 4(2), 305-308.

Kumar, A. (2007). Personal, Academic and Career Development in Higher Education-SOA Ring to Success London and New York, pp. 1-33. Routledge Taylor \& Francis Group.

Lawn, J. E., Kerber, K., Enweronu-Laryea, C., \& Cousens, S. (2010). 3.6 million Neonatal deaths-what is progressing and what is not?. Semin Perinatol., 34, 371-386.

Li, H. (2013). Newborn umbilical cord care in an Obstetrics and Gynecology Hospital in Shanghai: a best practice implementation project. The JBI Database of Systematic Reviews and Implementation Reports, $11(8), 565$.

Mahrous, E., Darwish, M., Dabash, S., Marie, I., \& Abdel El Wahab, S. (2012). Topical application of human milk reduces umbilical cord separation time and bacterial colonization compared to Ethanol in newborns. Translational Biomedicines, 3, 1-8.

Ministry of Health and Population, Egypt. (2014). Egypt Demographic and Health Survey 2014. Cairo, Egypt and Rockville, Maryland, USA: Ministry of Health and Population and ICF International.

Mohamed, A., Hassan, H., Gamel, W., \& Arafa, A. (2019). Awareness about breast and cervical cancers among nursing students in Beni-Suef University. Journal of Nursing Education and Practice, 9(5), 44-51. 
Mohamed, M. (2018). Effect of Umbilical Cord Care Intervention Program on mothers' Performance and Occurrence of Cord Problems among Their Newborn Infants I.

Moyer, C., Aborigo, A., Logonia, G., Affah, G., Rominski S., Adongo B., ... Engmann, C. (2012). Clean Delivery Practices in Rural Northern Ghana: A Qualitative Study of Community and Provider Knowledge, Attitudes, and Beliefs. BMC Pregnancy and Childbirth, 12(1).

Nandrup-Bus, I., \& Ugeskr, L. (2003). Evidence concerning umbilical cord hygiene in newborn infants. Pediatrics, 165(38), 3616-3619.

Nasr, E., \& Hassan, H. (2016). Association between quality of family planning services and client's satisfaction level in maternal and child health centers in Port Said city. Journal of Nursing Education and Practice, 6(1), 85-99.

Reza, S., \& Hassan, E. (2013). Knowledge assessment of neonatal care among postnatal mothers. Iranian Journal of Neonatology, 4(1), 28-31.

Said, S., Hassan, H., \& Sarhan, A. (2018). Effect of an Educational Intervention on Women's Knowledge and Attitude Regarding Cervical Cancer. American Journal of Nursing Research, 6(2), 59-66.

Sawardekar, K. (2004). Changing spectrum of neonatal omphalitis. Pediatr Infect Dis J., (23), 22-26.

Shahjahan, M., Ahmed, M., Rahman, M., \& Afroz, A. (2012). Factors Affecting Newborn Care Practices in Bangladesh. Paediatric and Perinatal Epidemiology, 26(1), 13-18.

Sheha, E., Hassan, H., \& Gamel, W. (2018). Association between pre-pregnant overweight and obesity and periodontal disease during pregnancy: a cross sectional study. International Journal of Studies in Nursing, $3(1), 1-21$.

Shrestha, T., Gautam, S., \& Silwal, K. (2013). Knowledge and practice of postnatal mother in Newborn care. Journal of Nepal Medical Association, 372-377.

Sinah, A., Sazawal, S., Pradhan, A., Ramji, S., \& Opiyo, N. (2015). Chlorhexidine skin or cord care for prevention ofmortality and infections in neonates. Cochrane Database of Systematic Reviews, 3(3), CD007835.

Sofiana dan Agustina. (2011). The effectiveness of Colostrums Methods and Methods of dry gauze with time release of the umbilical cord. Script Publication. Midwifery Academy YLPP Purwokerto, 3(2).

Susan \& Achora (2012). Knowledge, and Practice of Postnatal Mothers regarding Care of the Umbilical Cord stump. Retrieved from http://hdl.handle.net/10570/1531

The Joanna Briggs Institute, (2013). The University Adelaide. Retrieved from http://joannabriggslibrary.org/index.php/jbisrir/article/view/1257/1427

Whitmore, J. (2010). Newborn Umbilical Cord Care: An Evidence Based Quality Improvement Project. Doctor of Nursing Practice (DNP) Projects, 13. Retrieved from https://repository.usfca.edu/dnp/13

Wilson, D., \& Hockenberry, M. (2014). Wong's Clinical Manual of Pediatric Nursing (8th ed.), pp. 1233-1245. London, UK: Mosby.

World Health Organization. (2016, January). Fact Sheet No. 333.

Zahra, K., Zahra, A., Saber, M., \& Dehnavi, Z. (2018). The effect of small group teaching on quality of life in pregnant women with nausea and vomiting: A clinical trial. $J$ Edu Health Promot, 7, 112.

Zupan, J., Garner, P., \& Omari, A. (2004). Topical umbilical cord care at birth. Cochrane Database of Systematic Reviews, (3).

\section{Copyrights}

Copyright for this article is retained by the author(s), with first publication rights granted to the journal.

This is an open-access article distributed under the terms and conditions of the Creative Commons Attribution license (http://creativecommons.org/licenses/by/4.0/). 